\title{
MINAT BELAJAR DAN PENGETAHUAN AWAL SEBAGAI DETERMINASI HASIL BELAJAR
}

\author{
Neti Budiwati, Universitas Pendidikan Indonesia \\ netibudiwati@upi.edu
}

Teti Heryati, Sekolah Menengah Atas Negeri 1 Bandung

tetiheryati70@yahoo.com

Kinanti Geminastiti H, Universitas Pendidikan Indonesia

kinanti.gemi@upi.edu

\begin{abstract}
ABSTRAK
Rendahnya hasil belajar siswa dalam mata pelajaran Ekonomi dan Bisnis menjadi alasan penelitian ini, sehingga penelitian ini bertujuan untuk menidentifikasi faktor determinasi hasil belajar. Sampel penelitian adalah siswa kelas $\mathrm{X}$ Jurusan Pemasaran Sekolah Menengah Atas Negeri (SMKN) 1 Bandung. Data dikumpulkan melalui kuesioner tentang minat belajar Ekonomi dan Bisnis, serta dokumentasi terkait data pengetahuan awal dan data hasil belajar Ekonomi dan Bisnis. Metode penelitian adalah survey dengan alat pengumpul data angket model rating scale dan analisis data menggunakan teknik regresi linier berganda. Hasil penelitian menunjukkan bahwa minat belajar menjadi determinan hasil belajar siswa dalam mata pelajaran Ekonomi dan Bisnis, sedangkan pengetahuan awal tidak berpengaruh terhadap hasil belajar artinya pengetahuan awal siswa bukan merupakan determinasi hasil belajar pada mata pelajaran Ekonomi dan Bisnis
\end{abstract}

Kata Kunci: Minat Belajar, Pengetahuan Awal, Hasil Belajar.

\begin{abstract}
The low learning outcomes of students in Economics and Business subjects are the reason for this study, so this study has a purpose to identify the determinants of learning outcomes. The sample of the study was class $X$ students of the Marketing Department of State Senior High School (SMKN) 1 Bandung. Data was collected through questionnaires about interest in learning Economics and Business, as well as documentation related to initial knowledge data and data on learning outcomes of Economics and Business. Data analysis uses multiple linear regression techniques. The results showed that the interest in learning became a determinant of student learning outcomes in Economics and Business subjects, while the initial knowledge had no effect on learning outcomes meaning that the initial knowledge of students was not a determination of learning outcomes in Economics and Business subjects
\end{abstract}

Keywords: Learning Interest, Prior Knowledge, Leraning Outcomes. 


\section{PENDAHULUAN}

Belajar merupakan upaya sadar yang dilakukan seseorang agar dapat mencapai hasil yang diharapkan yaitu terjadi perubahan perilaku, yang secara nyata melalui proses belajar dan pembelajaran. Belajar merupakan pengalaman yang menunjukkan suatu proses runtun yang dialami oleh setiap orang.

Tujuan dari belajar bukanlah penguasaan hasil, melainkan perubahan tingkah laku ke arah yang lebih baik (Hamalik, 2010; Singh, Srivastava, \& Singh, 2015). Hasil belajar digambarkan sebagai perubahan perilaku yang dapat di ukur melalui proses pengamatan, pembuktian, dan pengukuran atas kemampuan atau hasil yang diperoleh anak didik. Hasil belajar merupakan gambaran atas kemampuan siswa yang diperolahnya melalui pengalaman belajar di sekolah (Nemeth \& Long, 2012; Molstad\&Karseth, 2016).

Terkait dengan hasil belajar sebagai perubahan perilaku merupakan sesuatu yang tidak sederhana dan pembelajaran sebagai proses yang kompleks dan multifaset (Ormrod, 2009), yang menyebabkan perubahan permanen dalam pengetahuan dan perilaku seseorang (Woolfolk, 1998; Santrock, 2001). Oleh karena itu perlu pengkondisian untuk setiap proses pembelajaran maupun siswa. Tidak ada sesuatu yang tidak dapat berubah selama ada upaya yang berkelanjutan.

Ada banyak faktor yang mempengaruhi hasil belajar, baik faktor internal yang menyangkut baik jasmani maupun rohani dan faktor eksternal termasuk faktor lingkungan (Syaodih, 2009). Siswa yang memiliki dukungan internal dan eksternal tentu diduga memiliki kapabilitas yang lebih untuk meraih hasil yang lebih baik. Dalam kenyataannya tidak semua siswa sekolah menengah kejuruan (SMKN) 1 Bandung, memiliki dukungan internal dan eksternal yang memadai, apalagi bagi siswa di sekolah menengah kejuruan (vokasional). Hasil studi pendahuluan pada siswa kelas X Pemasaran di sekolah menengah kejuruan I Bandung menunjukkan bahwa hasil belajar siswa belum optimal, yang terlihat sebagian besar hasil belajar belum mencapai standar ketuntasan minimal.

Hasil belajar yang rendah ini, diduga dipengaruhi beberapa faktor internal dan eksternal tersebut. Kasus pada sekolah menengah kejuruan 1 Bandung diduga dipengaruhi oleh faktor minat dan kemampuan awal yang dimiliki siswa. Minat merupakan sumber motivasi yang kuat bagi siswa untuk menjadi siswa yang aktif dan terlibat langsung dalam pembelajaran (Krapp, Hidi, \& Renninger, 1992; Syah, 2010), karena minat sesungguhnya merupakan menunjukkan karakteristik kepribadian seseorang yang sedang belajar (Chen, Yang, \& Hsiao, 2015).

Seorang siswa akan berhasil dalam pelajarannya apabila dalam diri siswa tersebut ada keinginan untuk belajar. Karena dengan keinginan besar dari dirinya untuk belajar akan memberi efek besar baik pada proses belajar maupun hasil yang dicapainya (Krapp, 2002). Konsekuensinya adalah bahwa bagaimana upaya guru mendorong siswa menyukai mata pelajarannya, sehingga dapat mengikuti pelajaran dengan fokus yang pada akhirnya memiliki kesediaan untuk mengerjakan soal-soal dan tugas yang diberikan guru (Alexander dkk.,1998). 
Selain itu hasil belajar siswa dalam mata pelajaran ekonomi dan bisnis diduga juga ditentukan oleh pengetahuan awal siswa tentang ekonomi, dalam hal ini adalah pengetahuan yang telah dimiliki siswa pada saat sekolah menengah pertama melalui pelajaran ilmu sosial. Pengetahuan awal siswa tentang ekonomi menunjukkan kesiapan siswa mengikuti kegiatan pembelajaran dan mempelajari ekonomi (Syah, 2010). Hasil penelitian dalam bidang matematika (Alexander dan Murphy, 1998; DeMarie et al., 2004) menunjukkan bahwa hasil belajar dijelaskan oleh pengetahuan sebelumnya yang telah dimiliki siswa. Oleh karena itu agar hasil belajar siswa dalam mata pelajaran ekonomi dan bisnis baik, maka guru diharapkan mengetahui kemampuan atau pengetahuan awal siswa tentang ekonomi. Ada keterkaitan antara apa yang telah dipelajari siswa (prior knowledge) dengan apa yang akan dipelajari atau dipahami siswa dalam kegiatan pembelajaran, ada keterhubungan antara pengetahuan dan kemampuan sebelumnya dengan pengetahuan dan kemampuan yang akan dipelajari saat ini. Kondisi yang terjadi pada saat sisiwa belajar di SMP, mata pelajaran ekonomi hanyalah bagian yang terintegrasi pada matapelajaran IPS Terpadu. Kondisi ini menyulitkan siswa untuk beradaptasi terhadap materi ajar ekonomi dan bisnis. Oleh karena itu perla dilakukan pretest agar mengetahui kemampuan siswa dalam setiap materi.

Siswa di sekolah menengah kejuruan (vokasional) kelas $\mathrm{X}$ yang belajar ekonomi pada mata pelajaran ekonomi dan bisnis, sebelumnya pernah belajar konsep-konsep ekonomi pada mata pelajaran ilmu pengetahuan sosial saat di sekolah menengah pertama. Oleh karena itu penelitian tujuan ini adalah untuk mengetahui sejauhmana pengetahuan siswa sebelumnya berkontribusi terhadap pencapaian hasil belajar ekonomi dan bisnis yang saat ini dijalani siswa.

Hasil belajar yang rendah tidak boleh dibiarkan, karena hasil belajar adalah orientasi pengalaman belajarnya dari kegiatan pembelajaran yang diikutinya (Nemeth \& Long, 2012; Molstad \& Karseth, 2016). Oleh karena itu perlu dicermati faktor yang diduga mempengaruhi hasil belajar siswa di sekolah menengah kejuruan 1 Bandung, sehingga penelitian ini mencermati dua faktor yaitu minat belajar dan pengetahuan awal yang diduga mempengaruhi hasil belajar siswa pada mata pelajaran ekonomi dan bisnis. Hal ini didasari pada keyakinan bahwa minat individu sebagai bentuk ketertarikan dan keinginan mendalam pada suatu bidang atau kegiatan yang timbul berdasarkan pengetahuan, emosi, pengalaman pribadi yang sudah ada sehingga menimbulkan pengalaman baru (Hidi, Berndoff; Ainley, 2002; Fryer, 2015), hasilnya dapat diukur dari hasil belajar yang dicapai siswa (Nemeth \& Long, 2012).

\section{METODE PENELITIAN}

Metode survey merupakan metode penelitian ini yang dimaksudkan untuk mengumpulkan informasi faktual melalui penggunaan kuesioner. Sampel penelitian diambil secara purposif pada dua kelas yang memenuhi kriteria dengan jumlah siswa 66 orang jurusan Pemasaran sekolah menengah kejuruan (SMKN) 1 Bandung. Data diperoleh dengan menggunakan angket model rating scale, untuk mengukur persepsi responden mengenai minat belajar yang 
diukur melalui indikator ketertarikan untuk belajar, perhatian dalam belajar, motivasi belajar dan pengetahuan. Hasil belajar siswa diperoleh berdasarkan nilai hasil ujian tes belajar. Analisis data untuk melihat pengaruh minat belajar dan pengetahuan awal terhadap hasil belajar menggunakan teknik regresi linier berganda dengan rumus regresinya adalah

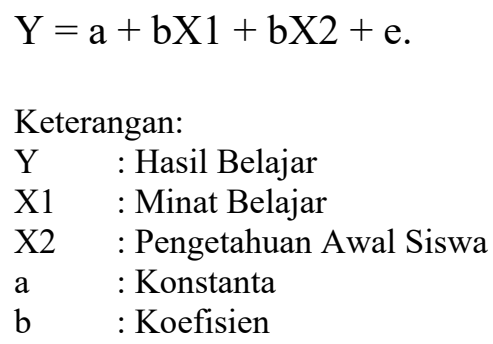

\section{HASIL PENELITIAN DAN PEMBAHASAN}

Sampel penelitian ini adalah siswa kelas $\mathrm{X}$ jurusan Pemasaran pada sekolah menengah kejuruan (SMKN) 1 Bandung, sebanyak 66 orang, terdiri dari 9 orang laki-laki dan 61 orang perempuan. Komposisi seperti ini merupakan hal wajar untuk sekolah menengah keahlian bisnis, sebaliknya justru terjadi pada sekolah menengah keahlian teknik yang dominan siswa lakilaki.

Hasil pengamatan langsung terhadap proses pembelajaran, minat belajar siswa cukup baik di kelas yang waktu belajarnya pagi (Pk 07.00 s.d 08.30), sedangkan minat belajar siswa yang belajar siang hari ( $\mathrm{Pk} 13.15$ s.d 14.45) terlihat tidak sebagus pada siswa yang belajar ekonomi dan bisnis pada pagi hari. Secara keseluruhan deskripsi minat tampak pada tabel 1.

Tabel 1. Gambaran Minat Belajar

\begin{tabular}{lcc}
\hline Kriteria Minat & Frekuensi & Persentase \\
\hline Tinggi & 18 & 27,27 \\
Sedang & 42 & 63,64 \\
Rendah & 9 & 0,09 \\
\hline Jumlah & 66 & 100,00 \\
\hline
\end{tabular}

Tabel 1. menjelaskan bahwa minat belajar siswa rata-rata berada pada kriteria sedang, hanya sedikit saja yang memiliki minat belajar tinggi. Minat belajar dilihat dari empat indikator yaitu kesukaan, ketertarikan, perhatian, dan keterlibatanterhadapmatapelajaranekonomi dan bisnis. Dilihat dari keempat indikator minat belajar, indikator keterlibatan terhadap terhadap mata pelajaran adalah yang paling rendah dan indikator kesukaan menempati posisi paling tinggi jika dibandingkan dengan indikator minar belajar lainnya.

Deskripsi pengetahuan awal siswa yang dilihat dari nilai mata pelajaran Ilmu Pengetahuan Sosial sekolah menengah pertama, tampak pada tabel 2 . Tabel 2. menjelaskan bahwa pengetahuan awal siswa sebagian besar pada kriteria sedang, hanya sedikit yang memiliki pengetahuan awal pada kriteria tinggi. 
Tabel 2. Gambaran Pengetahuan Awal Siswa

\begin{tabular}{lcc}
\hline Pengetahuan Awal & Frekuensi & Persentase \\
\hline Tinggi & 5 & 7,58 \\
Sedang & 51 & 72,27 \\
Rendah & 10 & 15,15 \\
\hline Jumlah & 66 & 100,00 \\
\hline
\end{tabular}

Untuk deskripsi hasil belajar ekonomi dan bisnis yang dilihat dari ratarata post-test tampak pada tabel 3. Tabel 3 menjelaskan bahwa hasil belajar siswa pada mata pelajaran ekonomi dan bisnis digolongkan masih rendah, karena lebih dari setengah siswa hasil belajarnya pada kriteria rendah. Dikatakan rendah yaitu dilihat dari jumlah siswa yang memiliki skor minat pada kriteria rendah lebih dari setengah responden yaitu sebanyak 54,55\% sedangkan skor tinggi haya diperolehsebesar 24,24\%, jadi secara keseluruhan dapat dikatakan bahwa hasil belajar siswa tergolong rendah.

Tabel 3. Gambaran Hasil Belajar

\begin{tabular}{lcc}
\hline Hasil Belajar & Frekuensi & Persentase \\
\hline Tinggi & 16 & 24,24 \\
Sedang & 14 & 21,21 \\
Rendah & 36 & 54,55 \\
\hline Jumlah & 66 & 100,00 \\
\hline
\end{tabular}

Dari kondisi tiga variabel di atas, maka selanjutnya data diolah untuk melihat keterkaitan antara dua variabel independen (minat belajar dan pengetahuan awal) dengan satu variabel dependen yaitu hasi belajar. Melalui olah data keterkaitan variabel diharapkan dapat menjelaskan kontribusi variabel minat belajar dan variabel pengetahuan awal terhadap variabel hasil belajar

Hasilpengolahan data denganbantuan program SPSS 21 forWindowsyaknisebagaiberikut:

Tabel 4. Kontribusi variabel Minat Belajar, Pengetahuan Awal Terhadap Hasil belajar

\begin{tabular}{llll}
\hline $\mathbf{R}$ & R Square & Adjusted Square & Sig. F. Change \\
\hline 0,506 & $\mathbf{0 , 2 5 6}$ & 0,232 & 0,000 \\
\hline
\end{tabular}

Tabel 5. Nilai Koefisiensi antar Katerkaitan Variabel

\begin{tabular}{lcc}
\hline Variabel & t hitung & Sig. t \\
\hline Nilai IPS SMP & 0,748 & 0,457 \\
Minat Belajar & 4,632 & 0,000
\end{tabular}

Tabel 4 dan 5 menjelaskan hasil pengolahan data bahwa kontribusi minat belajar dan pengetahuan awal siswa terhadap hasil belajarsebesar 25,6\%. Jika dilihat nilai signifikansnya maka minat belajar berpengaruh positif terhadap hasil belajar siswa, sedangkan pengetahuan awal siswa yang dilihat dari nilai mata pelajaran ilmu pengetahuan sosial sekolah menengah pertama tidak 
berpengaruh, karena signifikansi dari t hitung $>0,05$. Namun demikian model dari penelitian tersebut baik artinya minat belajar dan pengetahuan awal siswa dapat berkontribusi secara bersamaan terhadap hasil belajar hal ini dapat terlihat pada signifikansi $\mathrm{F}$ hitung $<0.005$.

Dengan demikian walaupun dengan kontribusi yang tergolong rendah minat belajar siswa menjadi determinasi hasil belajar siswa pada mata pelajaran ekonomi dan bisnis, sedangkan pengetahuan awal tidak berpengaruh terhadap hasil belajar sehingga tidak dapat dikatakan sebagai determinasi dari hasil belajar. Hasil yang menunjukkan rendahnya pengaruh minat terhadap hasil belajar dan pengetahuan awal tidak berpengaruh terhadap hasil belajar, mengindikasikan adanya faktor-faktor lain yang mempengaruhi hasil belajar.

Tidak berpengaruhnya pengetahuan awal terhadap hasil belajar menjadi menarik, karena berdasarkan beberapa hasil penelitian sebelumnya (Alexander dan Murphy, 1998; DeMarie et al., 2004; Smith,1991) menjelaskan bagaimana pengetahuan awal menjadi prediktor hasil belajar. Dijelaskan pula dalam penelitian Bransford dan Johnson (1973), adanya pengaruh pengetahuan awal terhadap pemahaman dan pemanggilan kembali pengetahuan/ide-ide yang telah dimiliki sebelumnya.

Implikasi temuan penelitian ini adalah bahwa harus ada upaya baik dari guru, orang tua/keluarga dan lingkungan untuk menumbuhkan minat belajar, agar hasil belajar yang dicapai siswa menjadi lebih baik. Karena orang-orang di sekitar siswa akan membentuk kondisi siswa termasuk belajar, karena minat berkaitan dengan rasa ingintahu yang terinspirasi atau dipengaruhi oleh lingkungan (Fryer, 2015; Flowerdayy \& Shell, 2015; Arnaldi, 2014), dan minat merupakan hasil interaksi seseorang atau individu dengan konten atau kegiatan tertentu (Schiefele, 2001).Oleh karena itu lingkungan belajar yang baik perlu diciptakan baik di rumah, di sekolah maupun lingkungan lainnya yang ada di sekitar siswa. Hal ini melihat gambaran tingkat minat siswa yang belum tergolong baik atau masih pada kategori sedang.

Terkait dengan faktor pengetahuan awal siswa yang tidak berpengaruh pada hasil belajar, tampaknya perlu di analisis dari berbagai sisi, karena sebagaimana dikatakan sebelumnya pengetahuan awal menjadi penentu hasil belajar. Perlu untuk dipahami beberapa hal berikut, yaitu: 1) Pengetahuan awal siswa tergolong cukup baik, namun bila mencermati keterkaitan materi ekonomi pada mata pelajaran Ilmu Pengetahuan sosial di sekolah menengah pertama dengan materi ekonomi dan bisnis tampak kurang signifikan, karena materi ekonomi di sekolah menengah pertama merupakan bagian dari materi ilmu sosial yang terintegrasi, sehingga konsep-konsep ekonomi tidak terlalu jelas. Karenanya materi keekonomian sebagai pengetahuan awal ini tidak memberi kontribusi apapun terhadap pemahaman siswa terhadap materi ekonomi dan bisnis di sekolah menengah kejuruan (SMK); 2) Materi pembelajaran ekonomi dan bisnis bersifat perpaduan antara teori/konsep dengan praktek, sehingga diduga pengetahuan awal siswa tidak cukup mendukung dan tidak linier terhadap materi ekonomi dan bisnis.

Materi pada mata pelajaran Ilmu Pengetahuan Sosial (IPS) di SMP merupakan materi terpadu antara beberapa pengetahuan sosial, yaitu materi sejarah, geografi, ekonomi dan sosiologi. Keemat materi pengetahuan sosial tersebut dikemas secara terpadu dalam kompetensi dasar (KD) yang bersifat 
tematik. Kondisi ini tentu saja tidak memberi bekal yang memadai bagi siswa, karena konsep-konsep materi ekonomi pada mata pelajaran IPS SMP merupakan tema-tema yang terintegrasi dengan materi pengetahua IPS lainnya. Dapat disimpulkan bahwa pengetahuan awal siswa dilhat dari nilai mata pelajaran IPS di SMP tidaklah tepat digunakan sebagai indikator pengatahuan awal siswa, perlu ada indisktor lain misalnya tes awal tentang ekonomi dan bisnis.

Sebagaimana diketahui bahwa salah satu jenjang pendidikan menengah yang bertujuan mempersiapkan lulusannya bisa langsung bekerja. Hal ini sejalan dengan data yang terindentifikasi yaitu bahwa hampir seluruh siswa yang memilih sekolah menengah kejuruan adalah mereka yang berorientasi untuk cepat mendapat pekerjaan, agar dapat membantu kondisi ekonomi keluarga yang rata-rata merupakan keluarga dengan ekonomi rendah. Keadaan demikian sejalan dengan teori human capital, yaitu bahwa pendidikan menjadi salah satu bentuk investasi.

Dengan memposisikan bahwa siswa belajar adalah bagian investasi orang tuanya mendorong siswa menjalani proses belajarnya untuk memperoleh berbagai keterampilan praktis yang kelak setelah lulus menjadi modalnya untuk dapat berkerja, sehingga dapat dimaklumi jika ternyata pengetahuan awal yang di ukur dari nilai mata pelajaran Ilmu Pengetahuan Sosial di sekolah menengah pertama tidak memiliki pengaruh terhadap hasil belajarnya saat ini. Ada ketidaksinkronan antara pengetahuan awal yang diukur dari nilai mata pelajaran IPS di SMP dengan materi ajar ekonomi dan bisnis di SMK.

Dilihat dari perolehan hasil belajar umumnya pada kriteria rendah dan masih jauh mencapai nilai ketuntasan minimal, hal ini sebagaimana dijelaskan oleh Slavin (2011), bahwa siswa yang berasal dari kelompok sosioekonomi kurang mampu rata-rata memperoleh nilai jauh dibawah kelompok sosioekonomi tinggi. Banyak keluarga dari kelompok ini yang tidak mampu menyediakan fasilitas belajar sebagai dukungan akademis anak-anaknya. Kondisi seperti ini juga merupakan gambaran para siswa yang menjadi sampel penelitian ini yang umumnya dari keluarga sosioekonomi rendah, dengan gambaran sebagian besar pendidikan orang tua pada jenjang sekolah dasar (SD) dan sekolah menengah pertama (SMP), dan sebagian besar berkerja sebagai buruh dan pedagang kecil. Oleh karena itu memilih sekolah menengah kejuruan (SMK) bagi anak-nakanya adalah pilihan yang tepat, agar anak kelak cepat berkerja untuk membantu kondisi ekonomi keluarga. Pendidikan kejuruan (SMK) adalah salah satu jenis pendidikan darisystempendidikan nasional yang mempersiapkan lulusannya memiliki bekal yang cukup agar dapat bekerja atau memiliki pekerjaan sesuai dengan bidang keahlian masingmasing.

Tidaklah salah jika pemerintah memiliki kebijakan memperluas dan memperbanyak jumlah dan daya tampung sekolah menengah kejuruan (SMK), mengingat kondisi kebanyakan keluarga pada masyarakat Indonesia sebagian besar masih tergolong kelompok sosial ekonomi tingkat menengah ke bawah. SMK menjadi pilihan kebanyakan anak dari keluarga menengah sosial ekonomi ke bawah, yang berharap segera memperoleh pekerjaan agar menghasilkan rate of return atau tingkat kembalian dari pendidikan yang diikutinya. Karenanya perlu diperhatikan muatan materi pada kurikulum SMK, 
agar benar-benar memberi bekal praktis bagi siswa memiliki pengetahuan dan keterampilan untuk mendapat pekerjaan atau berkerja untuk dirinya sendiri. Perlu ditanamamkan kebanggaan dan motivasi bagi siswa yang belajar di SMK agar tercipta pembelajaran efektif dengan hasil belajar praktis sesuai dengan tujuan SMK.

\section{SIMPULAN}

Hasil penelitian menunjukkan bahwa minat belajar menjadi determinan hasil belajar siswa dalam mata pelajaran Ekonomi dan Bisnis, sedangkan pengetahuan awal tidak berpengaruh terhadap hasil belajar artinya pengetahuan awal siswa bukan merupakan determinasi hasil belajar pada mata pelajaran Ekonomi dan Bisnis..

Pengetahuan awal siswa dilihat dari nilai mata pelajaran Ilmu Pengetahuan Sosial di sekolah menengah pertama (SMP) secara umumnya pada kriteria sedang atau cukup baik, sedangkan hasil belajar ekonomi dan bisnis pada kriteri rendah atau belum mencapai nilai ketuntasan minimal (KKM). Kondisi ini mengharuskan guru untuk melakukan remedial teaching sebelum melakukan remedial test.

Walaupun dengan tingkat koefesiensi determinasi yang rendah namun minat belajar menjadi determinasi hasil belajar, sedangkan pengetahuan awal tidak demikian. Kondisi ini menjelaskan bahwa ada fakor-faktor lain yang menjadi determinasi hasil balajar siwa.

\section{DAFTAR RUJUKAN}

Alexander, P. A., \& Murphy, P. K. 1998. Profiling the Differences in Students' Knowledge, interest, and strategic processing. Journal of Educational Psychology, 90(3), 435-447.

Alexander P. A., Kulikowich J. M., Schulze S. K. 1994. Am. Educ. Res. J. 31, 313-337. How Subject-MatterKnowledgeAffectsRecall and Interest $10.3102 / 00028312031002313$

Arnaldi, M. 2014. Four Factor Psychologies as Executive Function to Increase Interest of Learning. Procedia-Social Behavioral Science, 503-509.

Bransford, J.D. \& Johnson, M.K. 1973. Considerations of some Problems of Comprehension. Dalam W.G. Chase (Ed.)., Visual Information Processing. Orlando, FL: Academic Press.

Chen, S.-C., Yang, S. J., \& Hsiao, C.-C. 2015. Exploring Student Perception, Learning Outcome and Gender Defferences in a Flipped Mathematics Course. British Journal of Educational Technology.

DeMarie D., Aloise-Young P. A., Prideaux C. L., Muransky-Doran J., Gerda J. H. 2004. College Students' Memory for Vocabulary in Their Majors: 
Evidence for a NonlinearRelation BetweenKnowledge and Memory. Can. J. Exp. Psychol. 58, 181-195. 10.1037/h0087443.

Fryer, L. K. 2015. Predicting Self Concept, Interest and Achievement for First - Year Students: The Seeds of Lifelong Learning. Learning and Individual Differences.

Hamalik, Oemar. 2010. Proses BelajarMengajar. Jakarta: PT. BumiAksara Krapp, A. 2002. Structural and Dynamic Aspects of Interest Development: Theoretical Considerations From an Ontogenetic Perspective. Learning and Instruction , 12, 383-409.

Krapp, A., Hidi, S., \& Renninger, K. A. 1992. Interest, Learning, and Development. In A. Renninger, S. Hidi, \& A. Krapp (Eds). The Role of Interest in Learning and Development , 3-25.

Molstad, C. E., \& Karseth, B. 2016. National Curricula in Norway and Finland: The Role of Learning Outcomes. European Educational Research Journal , 15 (3), 329-344.

Syah, Muhibbin. 2010. Psikologi Pendidikan. Bandung: PT. Remaja Rosdakarya.

Nemeth, J., \& Long, J. G. 2012. Assessing Learning Outcomes in U.S. Planning Studio Courses. Journal of Planning Education and Research , 32 (4), 476-490.

Ormrod,J.E. 2009. Psikologi Pendidikan. (Terjemahan: Wahyu Indianti, dkk). Jakarta: Erlangga.

Santrock, J.W. 2001. Educational Psychology. New York: McGraw-Hill.

Schiefele, U. 2001. The Role of Interest in Motivation and Learning. In J. M. Collis, \& S. Messick (Eds.), Intelligence and Personality: Bridging the Gap in Theory and Measurement. Mahwah NJ: Lawrence Erlbraum Associate.

Singh, A. K., Srivastava, S., \& Singh, D. 2015. Student Engagement as The Predictor of Direct and Indirect Learning Outcomes in The Management Education Context. Metamorphosis , 14 (2), 20-29.

Syaodih, N. 2009. Pengembangan Kurikulum, Teori dan Praktik. Bandung: Remaja Rosdakarya.

Slavin. R. 2011, Psikologi Pendidikan, Teori dan Praktek (Terjemahan: Marianto Samosir). Jakarta: Indeks.

Woolfolk, A. E. 1998. Educational psychology. Boston: Allyn \& Bacon. 
